\title{
RELATIONSHIP BETWEEN PATELLAR HEIGHT AND RANGE OF MOTION AFTER TOTAL KNEE ARTHROPLASTY
}

Lúcio Honório de Carvalho Júnior', Luiz Fernando Machado Soares², Matheus Braga Jacques Gonçalves², Marcelo Lobo Pereira³ Rodrigo Rosa Lessa ${ }^{3}$, Lincoln Paiva Costa ${ }^{3}$

\section{ABSTRACT}

Objective: To evaluate whether, after total knee arthroplasty, there is any correlation between patellar height and range of motion (ROM) achieved by patients six months after the operation. Methods: Forty-five patients who underwent total knee arthroplasty were assessed at least 12 months after the operation (total of 54 knees). The maximum and minimum ROM of all the knees was recorded under fluoroscopy, along with patellar height according to the Blackburne and Peel ratio. Two possible correlations were evaluated: patellar height and ROM; and patellar height and ROM variation from before to after the operation. Results: A correlation was found between patellar height and postoperative ROM $(\mathrm{p}=0.04)$. There was no correlation between patellar height and ROM variation $(p=0.182)$. Conclusion: After total knee arthroplasty, the lower the patella is, the worse the ROM is.

Keywords - Arthroplasty Replacement Knee; Patella; Range of Motion, Articular.

\section{INTRODUCTION}

Total knee arthroplasty is one of the most often performed and most successful surgical procedures in the history of Orthopedics ${ }^{(1)}$. One of the objectives while performing the procedure is to restore the tensions between the collateral ligaments of the knee. To do this, the joint interline often undergoes relative elevation because the surgeon has to use polyethylene of greater thickness in order to adequately maintain the tensions in these ligaments ${ }^{(2)}$. Such changes in the height of the interline (and the consequent separation of the contact point between the femur and the polyethylene of the tibia) produces a relative lowering of the patellar height, such that it may become low. The objective of the present study was to evaluate whether, after total knee arthroplasty, there is any correlation between the pa- tellar height and the range of motion (ROM) achieved by the patient six months after the operation.

\section{METHODS}

Forty-five patients who underwent operations performed by the authors (total of 56 knees) at Hospital Madre Teresa, Belo Horizonte, were evaluated. After a minimum follow-up of 12 months, their arthroplasties were assessed under fluoroscopy. Through this, the maximum amplitudes of flexion and extension were recorded in lateral view, and the patellar height was measured using the Blackburne and Peel index ${ }^{(3)}$.

The patients' mean age was 73 years, with a range from 63 to 82 years. The mean length of postoperative follow-up was 28.9 months, ranging from 13 to 78 months.

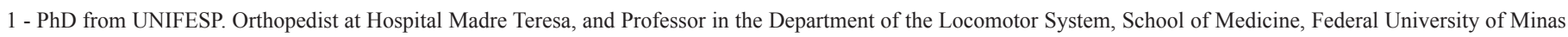
Gerais, Belo Horizonte, MG, Brazil.

2 - Orthopedist at Hospital Madre Teresa, Belo Horizonte, MG, Brazil.

3 - Resident Physician at Hospital Madre Teresa, Belo Horizonte, MG, Brazil.

Work performed at Hospital Madre Teresa, Belo Horizonte, MG, Brazil.

Correspondence: Rua Olavo Carsalade Vilela, 264, Ipê da Serra - 34000-000 - Nova Lima, MG - E-mail: luciohcj@medicina.ufmg.br

Work received for publication: May 30, 2010; accepted for publication: August 23, 2010.
}

The authors declare that there was no conflict of interest in conducting this work 
Two possible correlations were analyzed: the patellar height in relation to each patient's final ROM; and the relationship between this height and the change in ROM from before to after the operation.

The results were assessed using Pearson's test for independent variables, and $\mathrm{p}$ values were taken to be significant when they were less than 0.05 .

The prosthesis used for all the patients was the Nex Gen $^{\circledR}$, made by the company Zimmer ${ }^{\circledR}$ in Warsaw, Indiana, United States. In half of the cases, the posterior cruciate ligament (PCL) was sacrificed, and in the other half it was preserved; in the latter cases, a stabilized prosthesis was used. The patellar surface was not replaced in any of the patients.

Written consent was obtained from all the patients. This study was approved by our institution's research ethics committee.

\section{RESULTS}

The results are presented in Box 1. There was no significant difference in ROM between the two types of prosthesis.

The mean postoperative ROM was $105.6^{\circ}$, ranging from $85^{\circ}$ to $120^{\circ}$. In the cases of 34 patients, it was possible to obtain their ROM before the operation, from the medical files, and their mean was $110.73^{\circ}$, ranging from $80^{\circ}$ to $120^{\circ}$. In these patients, the mean patellar height before the operation was 0.90 , ranging from 0.6 to 1.15 . No extension deficit was found in any of the patients after the operation. Before the operation, the extension ranged from 0 to $20^{\circ}$ of flexion, with a mean of $8.5^{\circ}$.

The mean patellar height after the operation was 0.76 , ranging from 0.5 to 1.22 , which was considered to be a normal height, given that according to Blackburne and $\mathrm{Peel}^{3}$, their index would be normal when it was between 0.56 and 1.04 .

The change in ROM from before to after the operation was evaluated in 34 of the 56 patients. The mean change was a loss of $3.67^{\circ}$, ranging from a gain of $20^{\circ}$ to a loss of $40^{\circ}$ in relation to the preoperative situation. No limitation of extension was observed after the operation.

A correlation was observed between patellar height and ROM after the operation $(p=0.04)$. No correlation was observed between patellar height and the change in ROM ( $\mathrm{p}=0.182)$.

\section{DISCUSSION}

Postoperative radiological evaluations on total knee prostheses should follow objective and reproducible criteria. Some radiographic measurements are still poorly defined, such as the patellar height, since no index adapted for knee prostheses exists ${ }^{(4)}$. In the present study, the Blackburne and Peel index was used $^{(3)}$, because this takes into consideration the joint surface of the patella and a tangent to the joint surface of the tibial plateau, in lateral view. This measurement is reproducible, thus enabling comparison between before and after the operation.

After the operation, the patellar height is influenced by the height of the joint interline, which is defined by the tibial cut, distal femoral cut and thickness of the polyethylene. Thus, according to Chambat and Dejour apud Bonnin and Chambat ${ }^{(5)}$, the greater the bone resection and the thicker the polyethylene are, the lower the patella will be.

Aglietti and Binonapoli ${ }^{(6)}$ affirmed that in cases in which very thick polyethylene was needed in order to achieve knee stability (i.e. by keeping the collateral ligaments under tension), the patella would be low and that this would put the result at risk over the medium to long term after the procedure.

Figgie et $\mathrm{al}^{(7)}$ proposed, for cases in which the patellar surface was replaced, that the patellar component should be placed as proximally as possible, in order to compensate for the possibility of a low patella, either as a preexisting condition or after the operation. Because this component was not used in the cases analyzed in the present study, no comparison with the above authors' cases could be made.

According to the limits of the Blackburne and Peel index ${ }^{(3)}$, no cases of a truly low patella (less than 0.5 in the index) were found in the present study.

Stiffness subsequent to total knee arthroplasty is still a poorly defined topic. Despite the imprecision of its definition, its existence in situations in which accomplishing daily activities becomes impossible is accepted. Flexion of $65^{\circ}$ is needed for walking on a level surface, $100^{\circ}$ for going down stairs and more than $165^{\circ}$ for some religious or cultural practices ${ }^{(8,9)}$.

Several factors may influence ROM after total knee arthroplasty. Some of them are directly related to patients' characteristics before and after the operation (previous ROM, obesity and rehabilitation), 
Box 1 - Name, side, patellar height, ROM, sex, age and length of postoperative follow-up of the patients.

\begin{tabular}{|c|c|c|c|c|c|c|}
\hline Name & Knee & Patellar height & ROM & Sex & Age (years) & Follow-up (months) \\
\hline CAN & $\mathrm{R}$ & 0.8 & $110^{\circ}$ & $\mathrm{F}$ & 63 & 48 \\
\hline CFS & $\mathrm{R}$ & 0.8 & $105^{\circ}$ & $\mathrm{F}$ & 70 & 48 \\
\hline GNL & $\mathrm{R}$ & 0.6 & $120^{\circ}$ & $\mathrm{F}$ & 68 & 40 \\
\hline GNL & $\mathrm{L}$ & 1 & $120^{\circ}$ & $\mathrm{M}$ & 80 & 30 \\
\hline MGBS & $\mathrm{R}$ & 0.68 & $110^{\circ}$ & $\mathrm{F}$ & 80 & 20 \\
\hline MGBS & $\mathrm{L}$ & 0.62 & $105^{\circ}$ & $\mathrm{F}$ & 70 & 45 \\
\hline MZG & $\mathrm{L}$ & 0.64 & $115^{\circ}$ & $\mathrm{M}$ & 76 & 32 \\
\hline BMR & $\mathrm{L}$ & 0.5 & $90^{\circ}$ & $\mathrm{M}$ & 74 & 24 \\
\hline IASR & $\mathrm{R}$ & 0.59 & $90^{\circ}$ & $\mathrm{F}$ & 73 & 15 \\
\hline IASR & $\mathrm{L}$ & 0.78 & $85^{\circ}$ & $\mathrm{F}$ & 72 & 13 \\
\hline LJSO & $\mathrm{L}$ & 0.64 & $100^{\circ}$ & $\mathrm{F}$ & 71 & 21 \\
\hline MRTF & $\mathrm{L}$ & 0.88 & $110^{\circ}$ & $\mathrm{F}$ & 65 & 43 \\
\hline VSF & $\mathrm{R}$ & 0.79 & $110^{\circ}$ & $\mathrm{M}$ & 80 & 33 \\
\hline $\mathrm{CHS}$ & $\mathrm{R}$ & 0.77 & $115^{\circ}$ & $M$ & 82 & 44 \\
\hline DRVP & $R$ & 0.83 & $90^{\circ}$ & $\mathrm{F}$ & 77 & 43 \\
\hline DRVP & $\mathrm{L}$ & 0.83 & $90^{\circ}$ & $\mathrm{F}$ & 76 & 35 \\
\hline MFTCT & $\mathrm{R}$ & 0.75 & $110^{\circ}$ & $\mathrm{F}$ & 75 & 24 \\
\hline MFTCT & $\mathrm{L}$ & 0.82 & $110^{\circ}$ & $\mathrm{F}$ & 74 & 23 \\
\hline YSAS & $\mathrm{R}$ & 0.72 & $120^{\circ}$ & $\mathrm{F}$ & 70 & 17 \\
\hline PSAJ & $\mathrm{L}$ & 0.7 & $105^{\circ}$ & $\mathrm{F}$ & 64 & 16 \\
\hline MSSC & $\mathrm{R}$ & 0.76 & $90^{\circ}$ & $\mathrm{F}$ & 69 & 15 \\
\hline EGB & $\mathrm{L}$ & 0.69 & $100^{\circ}$ & $\mathrm{F}$ & 78 & 24 \\
\hline BKG & $\mathrm{R}$ & 0.76 & $90^{\circ}$ & $\mathrm{F}$ & 75 & 32 \\
\hline ZCS & $\mathrm{R}$ & 0.9 & $115^{\circ}$ & $\mathrm{F}$ & 74 & 18 \\
\hline NALP & $\mathrm{R}$ & 0.76 & $100^{\circ}$ & $\mathrm{F}$ & 73 & 23 \\
\hline EMC & $\mathrm{L}$ & 0.75 & $110^{\circ}$ & $\mathrm{F}$ & 72 & 28 \\
\hline AAA & $\mathrm{L}$ & 0.76 & $95^{\circ}$ & $M$ & 71 & 18 \\
\hline $\mathrm{SC}$ & $L$ & 0.73 & $110^{\circ}$ & $M$ & 70 & 32 \\
\hline RTO & $\mathrm{R}$ & 0.72 & $105^{\circ}$ & $\mathrm{F}$ & 80 & 33 \\
\hline AMB & $\mathrm{R}$ & 0.84 & $110^{\circ}$ & $M$ & 65 & 24 \\
\hline $\mathrm{AFQ}$ & $\mathrm{R}$ & 0.68 & $95^{\circ}$ & $\mathrm{F}$ & 67 & 32 \\
\hline VLB & $\mathrm{R}$ & 0.72 & $110^{\circ}$ & $\mathrm{F}$ & 68 & 27 \\
\hline VLB & $\mathrm{L}$ & 0.75 & $115^{\circ}$ & $\mathrm{F}$ & 69 & 27 \\
\hline LMR & $\mathrm{R}$ & 0.96 & $125^{\circ}$ & $\mathrm{F}$ & 81 & 24 \\
\hline EMGC & $\mathrm{R}$ & 0.9 & $100^{\circ}$ & $\mathrm{F}$ & 80 & 30 \\
\hline TNM & $\mathrm{R}$ & 0.8 & $115^{\circ}$ & $\mathrm{F}$ & 70 & 38 \\
\hline TNM & $\mathrm{L}$ & 0.79 & $120^{\circ}$ & $\mathrm{F}$ & 77 & 35 \\
\hline \multicolumn{7}{|c|}{ Second list of patients } \\
\hline SMSG & $\mathrm{R}$ & 0.93 & $100^{\circ}$ & $\mathrm{F}$ & 76 & 30 \\
\hline AS & $\mathrm{R}$ & 0.86 & $110^{\circ}$ & $\mathrm{F}$ & 75 & 26 \\
\hline MVM & $\mathrm{L}$ & 0.72 & $90^{\circ}$ & $\mathrm{F}$ & 73 & 26 \\
\hline GM & $\mathrm{R}$ & 0.68 & $100^{\circ}$ & $\mathrm{M}$ & 72 & 24 \\
\hline IP & $\mathrm{R}$ & 0.85 & $100^{\circ}$ & $\mathrm{F}$ & 71 & 32 \\
\hline AAM & $\mathrm{R}$ & 0.74 & $100^{\circ}$ & $\mathrm{F}$ & 73 & 20 \\
\hline BEM & $\mathrm{L}$ & 0.91 & $105^{\circ}$ & $\mathrm{F}$ & 73 & 19 \\
\hline MCA & $\mathrm{R}$ & 1.22 & $105^{\circ}$ & $\mathrm{F}$ & 72 & 18 \\
\hline ATVL & $\mathrm{L}$ & 0.8 & $100^{\circ}$ & $\mathrm{F}$ & 74 & 16 \\
\hline ATVL & $\mathrm{L}$ & 0.78 & $110^{\circ}$ & $\mathrm{F}$ & 71 & 18 \\
\hline MPB & $\mathrm{R}$ & 0.55 & $110^{\circ}$ & $\mathrm{F}$ & 75 & 15 \\
\hline MTSD & $\mathrm{L}$ & 0.6 & $115^{\circ}$ & $M$ & 73 & 14 \\
\hline DLF & $\mathrm{R}$ & 0.73 & $105^{\circ}$ & $\mathrm{F}$ & 74 & 24 \\
\hline DLF & $\mathrm{R}$ & 0.73 & $120^{\circ}$ & $\mathrm{F}$ & 74 & 78 \\
\hline RPA & $\mathrm{L}$ & 0.75 & $105^{\circ}$ & $\mathrm{F}$ & 76 & 75 \\
\hline MAP & $\mathrm{R}$ & 0.76 & $106^{\circ}$ & $\mathrm{F}$ & 75 & 40 \\
\hline MLP & $D$ & 0.77 & $104^{\circ}$ & $\mathrm{F}$ & 80 & 13 \\
\hline Mean & & 0.76 & $105.6^{\circ}$ & & 73 & 28.9 \\
\hline
\end{tabular}


while other relate to technical issues during the operation (errors in the flexion and extension breaks; resection of posterior osteophytes; preservation of the PCL; elevation of the joint interline; great final thickness of the patella; error in positioning the components; and design changes $)^{(10-12)}$. In the present study, the elevation of the interline and consequent change in patellar height were evaluated, in an attempt to isolate its influence on postoperative ROM. This is a limitation of the present stu$\mathrm{dy}$, since it is known that all the factors mentioned are interlinked.

In cases in which the patella remains low after implanting the prosthesis, the limitation on ROM may be due to direct mechanical impediment because of conflict of the patellar component or remnant bone of the lower pole of the patella against the anterior part of the tibial polyethylene ${ }^{(9)}$. Changes have been made to the design of the polyethylene in an attempt to minimize this risk $^{(10)}$.

The best way to predict the postoperative ROM after total knee arthroplasty is from the preoperative $\mathrm{ROM}^{(13)}$. The findings from the present study suggest that ROM magnitude may be negatively influenced in cases with great deformity and change in height of the patella, thus agreeing with the observations of several other authors ${ }^{(5,6,10-13)}$.

In the present study, fluoroscopy was chosen because of its practicality and the reliability of its measurements on the maximum extension and flexion of the knees evaluated.

\section{CONCLUSION}

After total knee arthroplasty, the lower the patella is, the smaller the range of motion of the operated knee will be.

\section{REFERENCES}

1. Deirmengian CA, Lonner JH. What's new in adult reconstructive knee surgery. J Bone Joint Surg Am. 2009;91(12):3008-18.

2. Krackow KA. The technique of total knee arthroplasty. Baltimore: Mosby; 1990.

3. Blackburne JS, Peel TE. A new method of measuring patellar height. J Bone Joint Surg Br. 1977;59(2):241-2.

4. Jacquot L, Chatain F, Casalonga $D$. Prothèse totale de genou et index rotulien. Chirurgie prothétique du genou. Montpellier Sauramps Médical. 1999; 283-92.

5. Bonnin M, Chambat P. Osteoarthritis of the knee : surgical treatment. França: Springer-Verlag ; 2008.

6. Aglietti P, Rinonapoli E. Total condylar knee arthroplasty. A five-year follow-up study of 33 knees. Clin Orthop Relat Res. 1984;(186):104-11.

7. Figgie HE 3rd, Goldberg VM, Heiple KG, Moller HS 3rd, Gordon NH. The influence of tibial-patellofemoral location on function of the knee in patients with the posterior stabilized condylar knee prosthesis. J Bone Joint Surg Am. 1986;68(7):1035-40.

8. Carvalho Júnior L, Castro CAC, Gonçalves MBJ, Rodrigues LCM, Cunha FVP, Lopes FL. Amplitude de movimento após artroplastia total do joelho Acta Ortop Bras. 2005;13(5):233-4.

9. Maeno S, Kondo M, Niki Y, Matsumoto H. Patellar impingement against the tibial component after total knee arthroplasty. Clin Orthop Relat Res. 2006;452:265-9.

10. Schurman DJ, Rojer DE. Total knee arthroplasty: range of motion across five systems. Clin Orthop Relat Res. 2005;(430):132-7.

11. Dennis DA, Komistek RD, Scuderi GR, Zingde S. Factors affecting flexion after total knee arthroplasty. Clin Orthop Relat Res. 2007;464:53-60.

12. Mihalko W, Fishkin Z, Krackow K. Patellofemoral overstuff and its relationship to flexion after total knee arthroplasty. Clin Orthop Relat Res. 2006;449:283-7.

13. Schurman DJ, Matityahu A, Goodman SB, Maloney W, Woolson S, Shi H, et al. Prediction of postoperative knee flexion in Insall-Burstein II total knee arthroplasty. Clin Orthop Relat Res. 1998;(353):175-84. 